\title{
HUBUNGAN KEMAMPUAN BERKOMUNIKASI GURU DENGAN MOTIVASI BELAJAR PADA MATA PELAJARAN BAHASA INDONESIA SISWA KELAS 1V SDN GUGUS 2 KECAMATAN PEMENANG KABUPATEN LOMBOK UTARA TAHUN PELAJARAN 2020/2021
}

\author{
Ilmiah Kartini ${ }^{1)}$, A. Hari Witono ${ }^{2)}$, I Nyoman Karma ${ }^{3)}$ \\ ${ }^{1,2,3)}$ Pendidikan Guru Sekolah Dasar, FKIP - Universitas Mataram \\ *Corresponding Author: ilmiahkartini@yahoo.com
}

\begin{tabular}{l}
\hline ARTICLE INFO \\
\hline Article history \\
Received: 5 Oktober 2020 \\
Revised: 17 Oktober 2020 \\
Accepted: 28 Oktober 2020 \\
Keywords: \\
Teacher's Communication Ability, \\
Learning Motivation in \\
Indonesian Language Subjects.
\end{tabular}

\section{ABSTRACT}

Penelitian ini bertujuan untuk mengetahui hubungan kemampuan berkomunikasi guru dengan motivasi belajar pada mata pelajaran Bahasa Indonesia siswa kelas IV SDN Gugus 2 Kecamatan Pemenang Kabupaten Lombok Utara tahun pelajaran 2020/2021. Populasi dalam penelitian ini adalah siswa kelas IV sebanyak 142 siswa. Sampel sebanyak 104 siswa yang diambil dengan teknik probability proportional random sampling dan besar sampel digunakan rumus Slavin. Teknik analisis data menggunakan rumus korelasi product moment, hasil analisis data didapatkan $\mathrm{r}$ hitung sebesar 0,444 dan $r$ tabel sebesar 0.1909 ( $r$ hitung $\geq r$ tabel) maka $\mathrm{Ha}$ di terima dan Ho di tolak, artinya ada Hubungan yang positif dan signifikan antara kemampuan berkomunikasi guru dengan motivasi belajar Bahasa Indonesia siswa kelas IV SDN Gugus 2 Kecamatan Pemenang Kabupaten Lombok Utara Tahun Pelajaran 2020/2021 dengan kategori sedang.

Kata Kunci: Kemampuan Berkomunikasi Guru, Motivasi Belajar Pada Mata Pelajaran Bahasa Indonesia.

This study aims to determine the relationship between teachers' communication skills and learning motivation in Indonesian language subjects for grade IV SDN Gugus 2, Pemenang District, North Lombok Regency, 2020/2021 academic year. The population in this study were 142 grade students. A sample of 104 people was taken using a probability proportional random sampling technique and the sample size used the Slavin formula. The data analysis technique uses the product moment correlation formula, the results of the data analysis show that $r$ count is 0.444 and $r$ table is 0.1909 ( $r$ count $\geq r$ table) then Ha is accepted and Ho is rejected, meaning that there is a positive and significant relationship between the teacher's communication skills and motivation to learn Indonesian for grade IV SDN Cluster 2 Subdistrict Pemenang, North Lombok Regency, Academic Year 2020/2021 in the medium category.

Keywords: Teacher's Communication Ability, Learning 


\section{A. PENDAHULUAN}

Pendidikan memiliki peranan yang sangat penting bagi kehidupan manusia. Sebagaimana yang terdapat dalam Undang - Undang nomor 20 Tahun 2003 pasal 3 tentang sistem pendidikan nasional, bahwa tujuan pendidikan nasional antara lain adalah mengembangkan potensi peserta didik agar menjadi manusia yang beriman dan bertakwa kepada Tuhan yang Maha Esa, berakhlak mulia, sehat, berilmu, cakap, kreatif, mandiri, dan menjadi warga negara yang demokratis serta bertanggung jawab. Dengan adanya pendidikan akan tercipta kepribadian yang mandiri serta rasa tanggung jawab dalam hidup bermasyarakat. Oleh karena itu setiap warga Negara berhak untuk mendapatkan pendidikan.

Meningkatkan motivasi belajar siswa merupakan tangung jawab seorang guru dalam mengajar. Berbagai hal yang mempengaruhi untuk membangkitkan motivasi belajar siswa, salah satunya adalah kemampuan seorang guru dalam berkomunikasi ketika proses pembelajaran, terutama dalam menyampaikan pelajaran kepada siswa. Dalam interaksi belajar mengajar, guru berperan sebagai pembimbing, (Sardiman:2016:17) dalam peranannya sebagai pembimbing ini, guru harus berusaha menghidupkan dan memberikan motivasi agar terjadi proses interaksi yang kondusif. Guru harus siap sebagai mediator dalam segala situasi proses belajar mengajar, sehingga guru merupakan tokoh yang akan di lihat dan akan ditiru tingkah lakunya oleh anak didik. Apabila guru mampu dalam menyampaikan pelajaran kepada siswa dengan interaksi yang baik dan benar maka apa yang disampaikan akan memperoleh hasil sesuai dengan yang diharapkan. Salah satu pengaruh yang ditimbulkan dari pengajaran yang dilakukan oleh guru kepada siswa bila dilakukan dengan benar adalah apa yang disampaikan oleh guru akan mudah dipahami dan dapat mempengaruhi terhadap peningkatan hasil belajar siswa. Suatu kondisi belajar yang menyenangkan apabila guru dapat menunjukkan sikap yang akrab, bersahabat dan memahami situasi di dalam kelas saat mengajar.

Dalam proses komunikasi, guru berfungsi sebagai sumber pesan dan siswa sebagai penerima pesan, begitupun sebaliknya yaitu guru sebagai penerima pesan dan siswa sebagai sumber pesan. Apabila komunikasi berjalan dengan baik maka hubungan antar individu juga baik begitu juga sebaliknya apabila terdapat miskomunikasi antar individu yang tengah melakukan komunikasi tentu akan berpengaruh juga terhadap hubungan antar individu. Guru sebagai pendidik tentunya akan melakukan yang terbaik untuk dapat mengembangkan segala potensi yang ada pada diri siswanya. Komunikasi antara guru dan siswa yang baik akan meningkatkan motivasi yang ada pada diri siswa. Dengan motivasi belajar, siswa menjadi tergerak untuk melakukan aktivitas belajar. Motivasi belajar yang ada pada diri siswa akan dapat timbul dengan adanya dorongan dari dalam diri siswa dimana dorongan tersebut di pengaruhi oleh gurunya. Dalam pembelajaran di perlukan sebuah komunikasi yang mampu mendorong serta mengarahkan siswa untuk mencapai tujuan pembelajaran. Sehingga komunikasi mampu mengantar siswa untuk berinteraksi, mengajak, mempengaruhi siswa, sehingga motivasi belajar pada diri siswa akan timbul 
dengan sendirinya. Setelah dilakukan observasi di kelas IV SDN Gugus V Kecamatan Gerung pada tanggal 31 Januari Tahun 2020 bahwa pada kenyataanya masih banyak guru di SDN Gugus 2 Kecamatan Pemenang yang belum mampu dalam berkomunikasi ketika menyampaikan pelajaran di dalam kelas, guru hanya memfokuskan kepada beberapa siswa, seperti siswa yang pintar saja, yang rajin saja dan lain sebagainya, komunikasi guru tidak ke semua arah, sehingga banyak siswa yang merasa bosan dan tidak semangat dalam mengikuti pelajaran, setelah di lakukan wawancara dengan beberapa siswa yang ada di SDN Gugus 2 Kecamatan Pemenang penyebab dari kurangnya kemampuan berkomunikasi guru Bahasa Indoneseia dalam mengajar adalah kurangnya keterampilan dalam berbahasa yang sesuai dengan peserta didik, misalnya guru berkomunikasi dengan siswa kelas empat menggunakan bahasa yang sesuai dengan siswa kelas satu begitupun sebaliknya, selain kurangnya kemampuan dalam berbahasa ketika menjelaskan pelajaran guru juga belum menguasai kelas, ketika mengajar guru hanya menggunakan satu metode yaitu ceramah saja, guru tindak menggunakan metode diskusi kelompok, demonstrasi dan lain sebagainya, sehingga menyebabkan siswa merasa bosan, mengantuk, dan tidak mau memperhatikan dengan serius ketika mengikuti pelajaran, dengan demikian akan menyebabkan motivasi belajar siswa rendah, jika motivasi belajar rendah maka hasil belajar siswa akan rendah pula.

Dari uraian tersebut di atas, menjadi dasar pemikiran bagi penulis dalam melakukan penelitian dengan judul: "Hubungan Kemampuan Berkomunikasi Guru dengan Motivasi Belajar Bahasa Indonesia Siswa Kelas IV SDN Gugus 2 Kecamatan Pemenang Kabupaten Lombok Utara Tahun Pelajaran 2020/2021”.

\section{B. METODE PENELITIAN}

Penelitian ini menggunakan pendekatan kuantitatif. Penelitian ini termasuk penelitian asosiatif (korelasional), penelitian ini biasa disebut dengan penelitian sebab akibat (kausal korelation). Sukardi (2008:166), menyatakan“penelitian korelasi merupakan suatu penelitian yang melibatkan tindakan pengumpulan data guna menentukan apakah ada hubungan dan tingkat hubungan antar variable".

Lokasi dalam penelitian ini di laksanakan di SDN Gugus 2 Kecamatan Pemenang Kabupaten Lombok utara, sekolah yang akan diteliti sebanyak 5 sekolah masing-masing diambil sampel sebagai berikut, SDN 1 Pemenang Barat terdiri dari 25 siswa, SDN 2 Pemenang Barat terdapat 20 siswa, SDN 4 Pemenang Barat terdapat 21 siswa, SDN 7 Pemenang Barat terdapat 25 siswa, dan SDN 8 Pemenang Barat terdiri dari 13 siswa, sehingga jumlah siswa kelas IV di SDN Gugus 2 Kecamatan Pemenang sebanyak 104 siswa.

Pada penelitian ini menggunakan teknik sampling probability sampling yaitu teknik pengambilan sampel yang memberikan peluang yang sama bagi setiap unsur (anggota) populasi untuk dipilih menjadi anggota sampel. Cara pengambilan sampel yang digunakan adalah proportional stratified random sampling. Data yang dibutuhkan dalam penelitian ini adalah data yang berkaitan dengan kemampuan berkomunikasi guru dan motivasi belajar pada mata pelajaran Bahasa Indonesia, sehingga metode pengumpulan data yang digunakan dalam penelitian ini adalah: 


\section{Angket (kuisioner)}

2. Dokumentasi

Adapun uji instrumen penelitian ini yang digunakan untuk menguji kelayakan instrumen untuk mengukur kemampuan berkomunikasi guru dengan motivasi belajar pada mata pelajaran Bahasa Indonesia, yaitu:

Uji instrumen dilakukan dengan :

1. Uji Validitas

2. Uji Reliabelitas

Teknik analisis data dilakukan dengan:

1. Uji normalitas data

$$
\mathrm{X}^{2}=\sum \frac{(f o-f e)^{2}}{f e}(\text { Chi Kuadra })
$$

2. Uji homogenitas

$$
\mathrm{F}=\frac{\text { varian besar }}{\text { varian kecil }}(\mathrm{Uji} \text { Varians) }
$$

3. Uji Linearitas

$$
r_{x y}=\frac{\sum x y}{\sqrt{\left(\Sigma \mathrm{X}^{2}\right)\left(\Sigma \mathrm{y}^{2}\right)}}(\text { Korelasi Product Moment })
$$

\section{HASIL DAN PEMBAHASAN}

Data hasil angket kemampuan berkomunikasi guru dan motivasi belajar peserta didik dapat dilihat pada tabel berikut:

Tabel 1. Deskripsi Variabel

\begin{tabular}{|l|c|c|c|c|c|}
\hline \multicolumn{1}{|c|}{ Variabel } & N & Min & Max & Mean & Keterangan \\
\hline Komunikasi Guru & 104 & 86 & 124 & 107.97 & $\begin{array}{c}\text { Cukup } \\
\text { Tinggi }\end{array}$ \\
\hline Motivasi Belajar & 104 & 93 & 138 & 120.01 & Tinggi \\
\hline Valid N (listwise) & 104 & & & & \\
\hline
\end{tabular}

Sumber: Data Primer Diolah (2021)

Berdasarkan hasil deskripsi variabel Komunikasi Guru dan Motivasi Belajar dengan 104 responden dapat dilihat bahwa pada variabel Komunikasi Guru memiliki nilai minimum 86 dan maksimum 124 dengan rata-rata 107.97 dan termasuk dalam kategori Cukup tinggi. Hal ini dapat diartikan bahwa komunikasi guru dalam menyampaikan materi Mata Pelajaran Bahasa Indonesia cukup baik.

Kemudian, pada variabel Motivasi Belajar, dapat dilihat nilai minimum yang dimiliki sebesar 93 dan maksimum 138 dengan rata-rata 120.01 dan masuk dalam kategori tinggi. Hal ini dapat diartikan bahwa motivasi belajar siswa dalam belajar Mata Pelajaran Bahasa Indonesia dilakukan dengan baik. 


\section{Uji Normalitas}

Tabel 2. Hasil Uji Normalitas Data Kemampuan Berkomunikasi Guru dan Tingkah Laku Motivasi belajar pada Mata Pelajaran Bahasa Indonesia Siswa

\begin{tabular}{|c|c|c|c|}
\hline Nilai Chi Hitung & Nilai Chi Tabel & Signifikansi & Keterangan \\
\hline 1266.014 & 124.34211 & 0.001 & Normal \\
\hline
\end{tabular}

Dari tabel diatas dapat dilihat bahwa $x^{2}$ untuk kemampuan berkomunikasi guru dan motivasi belajar dibandingkan dengan $x^{2}$ tabel sehingga dapat dinyatakan bahwa kedua data tersebut berdistribusi normal.

\section{Uji Homogenitas}

Tabel 3. Hasil Uji Homogenitas Data

\begin{tabular}{|c|c|c|c|}
\hline Levane Statistic & Signifikansi & Batas Minimal & Keterangan \\
\hline 0.605 & 0.437 & 0.05 & Homogen \\
\hline
\end{tabular}

Berdasarkan hasil uji homogenitas varian metode One Way Anova didapatkan data atau hasil yakni nilai signifikansi sebesar 0.437 lebih besar dari batas minimum atau alfa sebesar 0.05 sehingga dapat disimpulkan bahwa data yang digunakan pada penelitian ini bersifat homogen.

\section{Uji Hipotesis}

Tabel 4. Hasil Uji Hipotesis Data Kemampuan Berkomunikasi Guru dengan Motivasi Belajar pada Mata Pelajaran Bahasa Indonesia Siswa

\begin{tabular}{|c|c|c|}
\hline Deviation of Linierity & Signifikansi & Keterangan \\
\hline 1.160158 & 0.297 & Terdapat Hubungan Lineritas \\
\hline
\end{tabular}

Berdasarkan hasil uji lineritas menggunakan metode compare means hasil uji menunjukkan bahwa nilai Deviation of Linierity sebesar 1.160158 dan bernilai positif, sehingga motivasi belajar dengan komunikasi guru terdapat hubungan yang linear. Hal ini diperkuat dengan nilai signifikansi sebesar 0.297 lebih besar dari 0.05, sehingga hubungan linearitas ini menjadi hubungan yang signifikan

\section{Hasil Uji Korelasi}

Hasil uji korelasi merupakan bagian yang melihat hubungan antara variabel komunikasi guru dan motivasi siswa Belajar Bahasa Indonesia siswa kelas IV SDN Gugus 2 Kecamatan Pemenang Tahun Pelajaran 2020/2021. Hasil penelitian ini memiliki kriteria, jika nilai $r$ Hitung lebih besar dari $r$ Tabel maka terdapat hubungan antara komunikasi guru dengan motivasi belajar siswa. Selain itu, hasilnya diperkuat dengan jika nilai signifikansi lebih kecil dari 0.05 maka hubungan atau korelasi tersebut signifikan.

Berdasarkan hasil uji, korelasi antara komunikasi guru dengan motivasi belajar siswa ditunjukkan pada tabel sebagai berikut. 
Table 5. Hasil uji korelasi

\begin{tabular}{|c|c|c|c|}
\hline r Hitung & r Tabel & Signifikansi & Keterangan \\
\hline 0.489 & 0.1909 & 0.000 & Terdapat Korelasi \\
\hline
\end{tabular}

Sumber: Data Primer Diolah (2021)

Berdasarkan tabel hasil uji korelasi, dari hasil r Hitung sebesar 0.444 memiliki nilai lebih besar dari $\mathrm{r}$ Tabel sebesar 0.1909 maka terdapat korelasi atau hubungan antara komunikasi guru dengan motivasi belajar Bahasa Indonesia siswa kelas IV SDN Gugus 2 Kecamatan Pemenang Tahun Pelajaran 2020/2021.

\section{PENUTUP}

\section{Simpulan}

Berdasarkan hasil penelitian yang telah dilakukan maka dapat disimpulkan bahwa ada hubungan antara kemampuan berkomunikasi guru dengan motivasi belajar pada mata pelajaran Bahasa Indonesia siswa kelas IV SDN Gugus 2 Kecamatan Pemenang Tahun pelajaran 2020/2021. Hal ini ditunjukkan Berdasarkan hasil deskripsi variabel Komunikasi Guru dan Motivasi Belajar dengan jumlah 104 responden dapat diketahui bahwa pada variabel Komunikasi Guru memiliki nilai minimum 86 dan maksimum 124 dengan rata-rata 107.97 dan termasuk dalam kategori "Cukup tinggi" selanjutnya pada variabel motivasi belajar dapat diketahui nilai minimum yang dimiliki sebesar 93 dan maksimum 138 dengan rata-rata 120.01 dan masuk dalam kategori "tinggi". Hal ini dapat diartikan bahwa motivasi belajar Mata Pelajaran Bahasa Indonesia dilakukan dengan" baik".

Selanjutnya dari hasil analisis data tentang hubungan kemampuan berkomunikasi guru dengan motivasi belajar dapat disimpulkan bahwa terdapat hubungan yang positif dan signifikan antara Kemampuan Berkomunikasi Guru dengan Motivasi Belajar pada Mata Pelajaran Bahasa Indonesia Siswa Kelas IV SDN Gugus 2 Kecamatan Pemenang Kabupaten Lombok Utara Tahun Pelajaran 2020/2021. Hal ini ditunjukkan dengan hasil analisis data menggunakan korelasi Pearson Product Moment dengan $\mathrm{r}$ hitung lebih besar dari pada $\mathrm{r}$ tabel dengan $\mathrm{N}=104$ pada taraf signifikan 5\% yaitu $\mathrm{r}_{\text {hitung }}$ sebesar 0.444 memiliki nilai lebih besar dari $r r_{\text {tabel }}$ sebesar 0. 1909. Menunjukkan tingkat hubungan yang sedang. Maka $\mathrm{H}_{0}$ (hipotesis nihil) yang diajukan ditolak dan sebaliknya $\mathrm{H}_{\mathrm{a}}$ (hipotesis alternative) diterima, pada taraf signifikansi 5\% sehingga hasil penelitian ini dapat dinyatakan "signifikan".

\section{Saran}

Berdasarkan kesimpulan yang telah dikemukakan di atas, peneliti menyampaikan saransaran sebagai berikut:

1. Diharapkan guru bisa lebih menyiasati penyampain materi pelajaran dengan metode pengajaran yang lebih menarik agar siswa tidak mengalami kejenuhan untuk mengikuti pelajaran dan tanpa harus mengurangi esensi dari materi yang disampikan, hal ini bisa disiasati dengan penyampaian materi yangdiselingi permainan-permainan yang dapat membuat siswa terhibur. 
2. Bagi sekolah, diharapkan lebih dapat memahami dan mendorong terwujudnya peningkatan kemampuan berkomunikasi guru sehingga dapat meningkatkan sumber daya guru seacara keseluruhan khususnya kelas IV. Sehingga guru dan sekolah diharapkan dapat membangun komunikasi yang efektif dalam melakukan proses pembelajaran.

3. Bagi peneliti selanjutnya, yang ingin untuk melaksanakan penelitian yang serupa hendaknya untuk mengadakan penelitian yang lebih luas berkaitan dengan kemampuan berkomunikasi guru dengan motivasi belajar pada mata pelajaran yang lainnya.

\section{DAFTAR PUSTAKA}

Arikunto, Suharsimi. 2013. Prosedur penelitian suatu pendekatan praktik. Jakarta: Rineka Cipta.

Astuti Arin Nur, 2012. Hubungan Kemampuan Berkomunikasi Guru dengan Motivasi Belajar Matematika. Jurnal penelitian 2012:85. Yogyakarta: FKIP UNY.

Uno, Hamzah B, 2016. Teori Motivasi Belajar dan Pengukurannya. $\quad$ Gorontalo: Bumi Aksara.

Daryanto, 2015. Teori Komunikasi. Malang: Gava Media.

Depdiknas, 2006. Permendiknas No 20 Tahun 2003 pasal 3 tentang sistem pendidikan nasional. Jakarta: Depdiknas.

Hadi Sutrisno. 2016. Statistik.Yogyakarta: Pustaka Pelajar.

Keraf Gorys. 1970. Komposisi. Jakarta: Nusa Indah.

Sardiman. 2016. Interaksi dan motivasi belajar mengajar. Jakarta: Rajawali Press

Saputra Haditya. 2013. Studi Tentang Kemampuan Berkomunikasi Guru Dalam Meningkatkan Motivasi Belajar Siswa Pada Kegiatan Belajar Mengajar,Fisipol: Samarinda.

Sugiyono, 2016. Metode penelitian kuantitatif, kualitatif, dan R dan D. Bandung: Alfabeta Bandung.

Sukardi, 2013. Metodologi Penelitian Pendidikan, Jakarta: Bumi Aksara.

Syatra, Nuni Y. 2016. Desain Relasi Efektif Guru dan Murid. Jogjakarta: Buku biru. 